
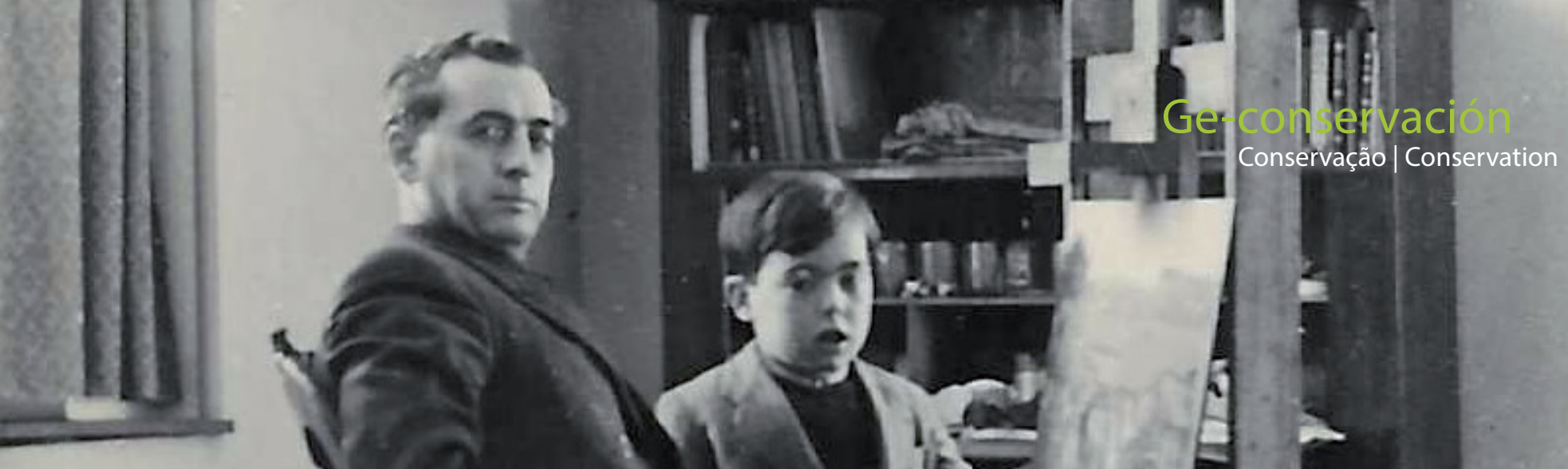

\title{
O pintor-restaurador Albino Moreira da Cunha. Contextualização da sua atividade no panorama cultural português do século XX
}

\author{
Virgínia Glória Nascimento, Fernando António Baptista Pereira, António Candeias, Alice \\ Nogueira Alves
}

\begin{abstract}
Resumo: Albino Moreira da Cunha nasceu no Porto em 1897 e foi nessa cidade que iniciou a sua atividade como pintor-decorador, mudandose posteriormente para Lisboa, onde o seu trabalho de reintegração se destacou durante o restauro do Palácio Nacional de Queluz. A sua atividade como pintor-restaurador surge associada à figura de Fernando Mardel e à oficina de restauro do Estado localizada no antigo Convento de São Francisco, em Lisboa. Contudo, apesar da importância que alcançou no meio artístico e cultural, esta sua faceta está ainda por estudar.

Recorrendo às fontes documentais, procuramos reconstruir o seu percurso profissional, contextualizando a sua atividade no meio artístico e cultural português, com o objetivo de contribuir com novos dados sobre a atividade dos pintores-restauradores em Portugal em meados do século XX, um tema sobre o qual ainda há muito por descobrir.
\end{abstract}

Palavras-chave: pintura, restauro, Portugal, século XX

\section{The painter-restorer Albino Moreira da Cunha. Contextualization of his activity in the 20th century Portuguese cultural scene}

\begin{abstract}
Albino Moreira da Cunha was born in Oporto in 1897 and it was there that he began his activity as a painter-decorator, moving later to Lisbon where his reintegration ability stood out during the restoration works of the National Palace of Queluz. His activity as painter-restorer is associated to Fernando Mardel and to the restoration workshop located at the old Convento de São Francisco, Lisbon. However, despite the importance he achieved in the artistic and cultural milieu, this part of his life is yet to be studied.
\end{abstract}

From the documental sources we try to trace back his professional background, contextualizing his activity in the Portuguese artistic and cultural context, with the goal to add new data on the activity of painter-restorers in Portugal in mid 20th century, a subject on which there is much to discover.

Keywords: painting, restoration, Portugal, $20^{\text {th }}$ century

\section{El pintor-restaurador Albino Moreira da Cunha. Contextualizado de su actividad en el panorama cultural portugués del siglo XX}

Resumen: Albino Moreira da Cunha nació en Oporto en 1897 y fue en esa ciudad que empezó suactividad como pintor-decorador, trasladándose posteriormente a Lisboa, donde se destacó por su trabajo de reintegración durante la restauración del Palacio Nacional de Queluz. Su actividad como pintor-restaurador se asocia a Fernando Mardel e a la oficina de restauro del Estado ubicada en el antiguo Convento de São Francisco, en Lisboa. Sin embargo la importancia que alcanzó en el circulo artístico e cultural, esta parte de su vida está aún por estudiar.

A partir de fuentes documentales, tratamos de reconstruir su precursor laboral, encuadrando su actividad en el medio artístico y cultural portugués, con el objetivo de aportar nuevos datos sobre los pintores-restauradores en Portugal a mediados del siglo XX, un tema sobre lo cual hay mucho que descubrir.

Palabras clave: pintura, restauro, Portugal, siglo XX 


\section{Albino Moreira da Cunha}

Albino Moreira da Cunha nasceu no Porto, na Cedofeita, a 17 de setembro de 1897 (Diário de Lisboa 12/4/1970) e foi nessa cidade que iniciou a sua formação artística, primeiramente na Academia de Belas-Artes do Porto, onde frequentou o curso de Pintura entre 1912 e 1913 (FBAP, Inventário Alumni 1836-1957), e, posteriormente, na Escola Industrial Faria de Guimarães, no curso noturno de Desenho Ornamental (Catálogo da Exposição de Pintura de Albino Cunha no Salão «Silva Porto» 1946; Moreira Lobo 1998).

A sua passagem pela Escola Faria de Guimarães foi uma etapa relevante no seu percurso profissional como pintordecorador e terá sido nesse contexto que, por volta de 1919, conheceu o pintor Leal da Câmara ${ }^{[1]}$, com quem colaborou na decoração do Pavilhão das Industrias Portuguesas na Exposição Internacional do Rio de Janeiro em 1922 (Catálogo da Exposição de Pintura de Albino Cunha no Salão «Silva Porto» 1946; Rodrigues 2013).

Nos anos seguintes dedicou-se à produção pictórica, expondo em 1924 no Salão da Fotografia Bobone em Lisboa $^{[2]}$ e, em 1926, no Salão da Misericórdia do Porto (Catálogo da Exposição de Pintura de Albino Cunha no Salão «Silva Porto» 1946; Ilustração n.o 97 1930). Em 1927 vai para Paris, numa época em que já tinham regressado a Portugal os artistas portugueses ligados à 14 Cité Falguière, como Diogo de Macedo, Domingos Rebelo ou Amadeu de Sousa-Cardoso, artistas que admirava e dos quais possuía obras na sua coleção particular (O Século 26/1/1971).

Da sua «larga peregrinação de estudo» a França resultaram várias obras que expõe em 1929 no Salão Silva Porto, na cidade do Porto, e que são, segundo a crítica, «[...] excelentes testemunhos dos seus progressos artísticos, dos seus estudos em Paris [...]» (Ilustração n. 97 1930). Contudo, apesar das referências que surgem nas publicações periódicas da época, como por exemplo na revista Cinéfilo (Cinéfilo 20-45 1929), não dispomos de dados que nos permitam compreender melhor a sua atividade artística em Paris durante este período. Sabemos que entre 1931 e 1940 participou no Salon de Paris (AA.VV. 1963; Benezit 1976, Santos 2020), facto este que indica que se teria integrado bem na cena artística parisiense e que, após regressar a Portugal, se deslocava com regularidade à capital francesa.

Em 1930 já residia em Lisboa, na Rua Garrett (Ficha de Identificação do Ginásio Clube Português, PT-GCP/ FIS/5095), no mesmo edifício onde existiu o Café Chiado, que era na época 0 "[...] ponto de convergência de intelectuais, políticos, artistas, jornalistas, estudantes e boémios [...]» (O Século 26/1/1971), o que supomos terá facilitado a sua aproximação ao meio artístico e intelectual. Ao longo dos anos tornou-se «uma figura que fazia parte da paisagem do Chiado» (O Século 26/1/1971), mas também da vida cultural lisboeta, sendo aceite em 1938 como sócio do Grupo «Amigos de Lisboa» (Olisipo n. 3 Agosto 1938).
Foi como «artista pintor» que participou nas obras de restauro e de decoração do Palácio Nacional de Queluz em 1934, onde fez trabalhos de pintura decorativa dos «[...] ornatos de pasta nova, do teto e paredes [...]» (SIPA TXT.01751720). Para além deste trabalho, e em colaboração com Pedro de Lemos Correia, ficou encarregue do douramento de várias salas do palácio (SIPA TXT.01751603, SIPA TXT.01751800), da substituição dos espelhos na Sala do Trono (SIPA TXT.01751603), e, segundo supomos, dos trabalhos de douramento, pinturas lisas, marmoreados e esponjados que foram levados a cabo na Sala da Música. Esta obra foi sem dúvida um momento de viragem na vida de Albino Cunha. As duas maquetas e os estudos do Palácio de Queluz, incluídos no leilão que se realizou em 1971, após a sua morte (BA-FCG - CDEM, O Século de 26/1/1971), deixamnos adivinhar a importância que este trabalho teve seu percurso profissional, pelo gosto que adquiriu pelo restauro, mas sobretudo, pelos contactos que estabeleceu e que irão proporcionar-Ihe oportunidades de trabalho como pintordecorador, e também, como pintor-restaurador [Figura 1].

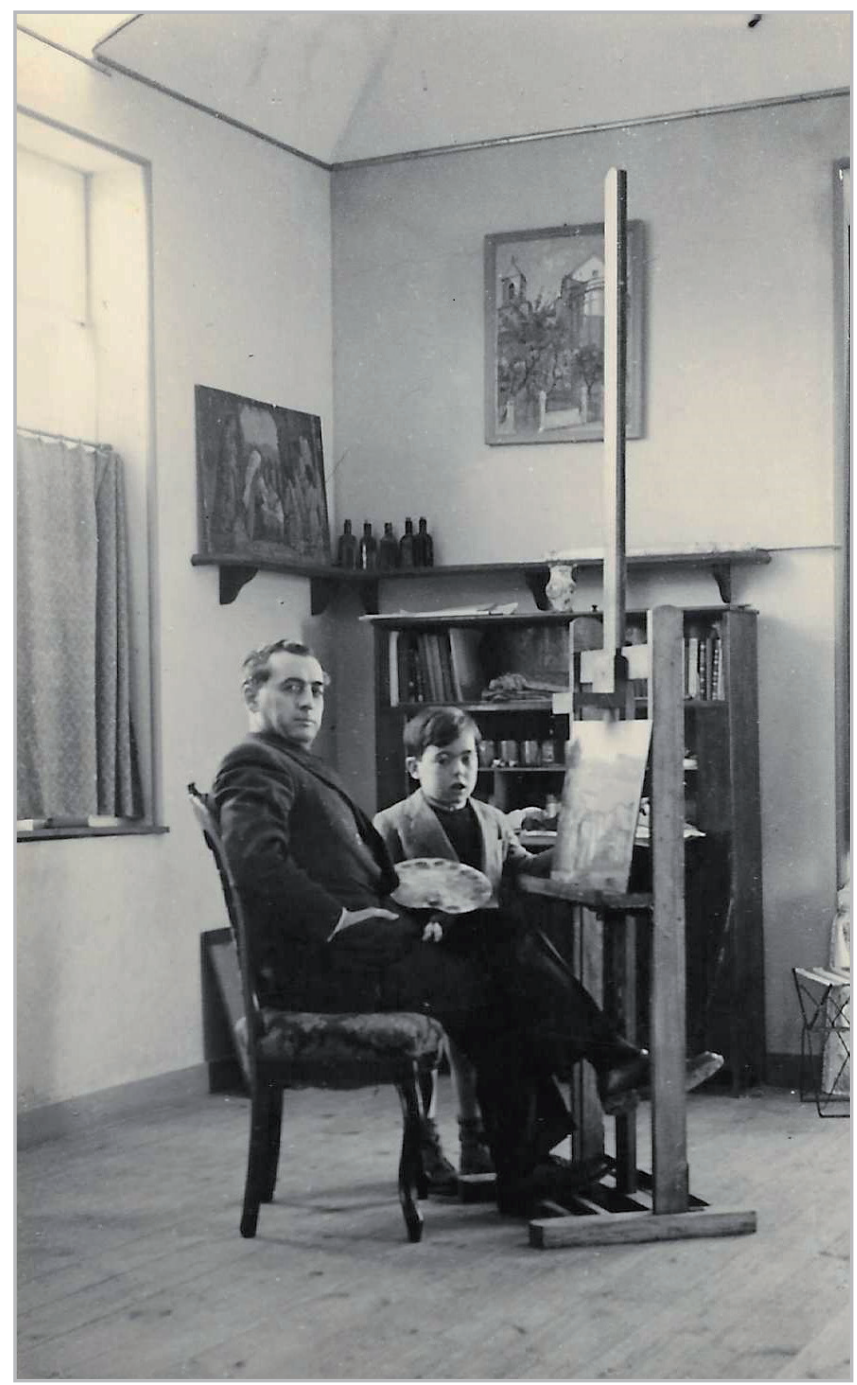

Figura 1.- Albino Moreira da Cunha com o neto Albino Fernando da Cunha Tocha. No atelier da vivenda de S. João, Belas - Idanha, Agosto 1946. @Arquivo familiar dos descendentes de Albino Moreira Cunha. 
Enquanto «pintor d'arte» participou em 1934 na 31. Exposição da Sociedade Nacional de Belas-Artes (SNBA), dedicada à pintura e à aguarela, juntamente com artistas como Malhoa, Velozo Salgado ou Emmerico Nunes (Ilustração n. 200 1934). Ao longo dos anos apresentou a sua obra com frequência em exposições organizadas pela $\mathrm{SNBA}^{[3]}$, durante as quais o Museu Nacional de Arte Contemporânea (MNAC) compra a pintura Sala Azul (Palácio da Ajuda), em 1936, Arco Sétimo Severo (Roma), em 1939, e Flores (guache), em 1944 [DGPC MNAC n.oinv.1056](Perez 2012).

Entre 1939 e 1940, integra a equipa encarregada da decoração da Casa de Santo António na Grande Exposição do Mundo Português (Comissão Nacional dos Centenários 1940), e, ao que se julga, terá sido o autor das «[...] reproduções pictóricas das tábuas de Frei Carlos, Gregório Lopes, Francisco Henriques e mestre de Ancede [...]» (Revista dos Centenários 1940). É possível que uma dessas reproduções seja «[...] o quadro «Santo António» de Frei Carlos, cópia de Albino Cunha, pintura a óleo sobre madeira. [...]», que a Câmara Municipal de Lisboa enviou em 1953 para o Pavilhão de Lisboa do Portugal dos Pequeninos em Coimbra (CML 1954), o que nos indica que também se dedicou à execução de cópias, embora esta seja a única referência documental que encontramos a esse tipo de trabalho.

Nesta época, volta a expor publicamente os seus trabalhos no Salon de Paris. Em 1944 participa e ganha a primeira medalha de pintura no Salão de Inverno da SNBA (Acciaiuoli 1991), realizando uma exposição individual na mesma instituição dois anos mais tarde (Brito 1991). Em 1947, depois de uma viagem por Espanha, apresenta obras com temas espanhóis e portugueses no salão Dardo, em Madrid, sendo bem-recebido pela crítica, que salienta o «[...] templado criterio realista y que en su cuadros de interiores, sobre todo nos lia dejado notas sensibles dé intimismo, con sobriedad de trazos y las inás entonada armonías de color y de ambiente [...]» (ADB Madrid 8/7/1947). Nesse mesmo ano, recebe a segunda medalha de aguarela no Salão de Inverno da SNBA (Brito 1991).

Em 1949, é novamente premiado com a primeira medalha de pintura no Salão de Primavera da SNBA (Brito 1991) e expõe individualmente no Salão Silva Porto, no Porto (Catálogo da Exposição de Pintura de Albino Cunha no Salão «Silva Porto» 1946). Onze anos mais tarde, expõe, juntamente com outros artistas, na Cooperativa Fraternidade Operária Ajudense (Panorama 1960), sendo esta a última exposição de que temos registo.

Como pintor ficou conhecido pela «exatidão e minúcia» das sua pintura de interiores (Ilustração n. 249 1936), visível nos registos das salas do palácio Nacional de Queluz, do Palácio Nacional da Ajuda [DGPC PNA n.o inv. 58388] e do Palácio Real em Espanha (Europeana - Albino Cunha), e, pelos retratos «[...] marcados pelo rigor das caraterísticas anatómicas de muitas personalidades, algumas das quais de relevante situação na sociedade portuguesa [...]», como, por exemplo, o retrato de 1941 do olisopógrafo Gustavo de Matos Sequeira, vice-presidente do Grupo "Amigos de Lisboa" (Museu de Lisboa - Coleção online).

Albino Cunha foi discípulo dos pintores portuenses Marques de Oliveira ${ }^{[4]}$ e Joaquim Lopes ${ }^{[5]}$ (Santos 2020), seguindo a formação neoclássica «[...] quer nos processos de execução, que na conceção dos seus trabalhos [...]». A sua obra pictórica poderá ser enquadrada no realismo sensorial, que remonta ao naturalismo do século XIX e que se baseia no imediatismo sensorial (MNACRS Folleto El retorno de lo imaginario), e por isso, o pintor não seguiu os movimentos modernistas do Porto e de Lisboa (O Século de 26/1/1971), o que, na década de 40, Ihe valeu duras críticas por parte da revista Seara Nova, apontando a sua «falta de sentido de composição» (Seara Nova 803-854 1943; Seara Nova 908959 1945).

A sua habilidade para reproduzir pictoricamente o real é notória no trabalho que desenvolveu entre 1935 e 1945, juntamente com o escultor Joaquim Barreiros, na reprodução das manchas da pele da Coleção Ceroplástica da Sociedade Portuguesa de Dermatologia e Venerealogia (Tacão 2010; Jornal Expresso 28/5/2016). E foi esta capacidade técnica de mimetizar o que via que explorou nos trabalhos de integração cromática enquanto pintor-restaurador.

\section{O pintor-restaurador}

As primeiras referências que encontramos à sua atividade como restaurador surgem na documentação de 1934 associada ao restauro do Palácio Nacional de Queluz, na qual Albino Moreira da Cunha se apresenta como «artista pintor» (SIPA TXT.01751720) e concorre contra Ubaldo F. Mardel de Araújo «pintor, restaurador do Museu de Arte Antiga e dos Museus Regionais» (SIPA TXT.01751702, TXT.01751703) para a execução das obras do quarto de Toilette de D. Carlota Joaquina.

Apesar desta obra ter sido adjudicada a Albino Cunha, é possível que com o decorrer dos trabalhos os dois concorrentes tenham estabelecido contacto e colaborado no restauro dos tetos das Salas dos Embaixadores, do Conselho e de D. Quixote (AA.VV. 1963). Certo é que a relação pessoal e profissional que se estabeleceu entre estes dois pintores-restauradores parece ter-se consolidado ao longo dos anos seguintes, como sugere o retrato de Fernando Mardel que em 1935 Albino Cunha dedica «ao ser grande Amigo e mestre» (DGPC - MatrizNet Retrato de Fernando Mardel) [Figura 2] [DGPC MJM n. ${ }^{\circ}$ inv. Pin 343].

Nesta época Fernando Mardel dirigia a Oficina de Restauro do Estado, localizada no antigo Convento de São Francisco em Lisboa, que estava ligada ao Museu Nacional de Arte Antiga e que havia sido criada em 1911, um ano após Luciano Freire apresentar o resultado do restauro dos Painéis de São Vicente e de ter sido constituída a Comissão 


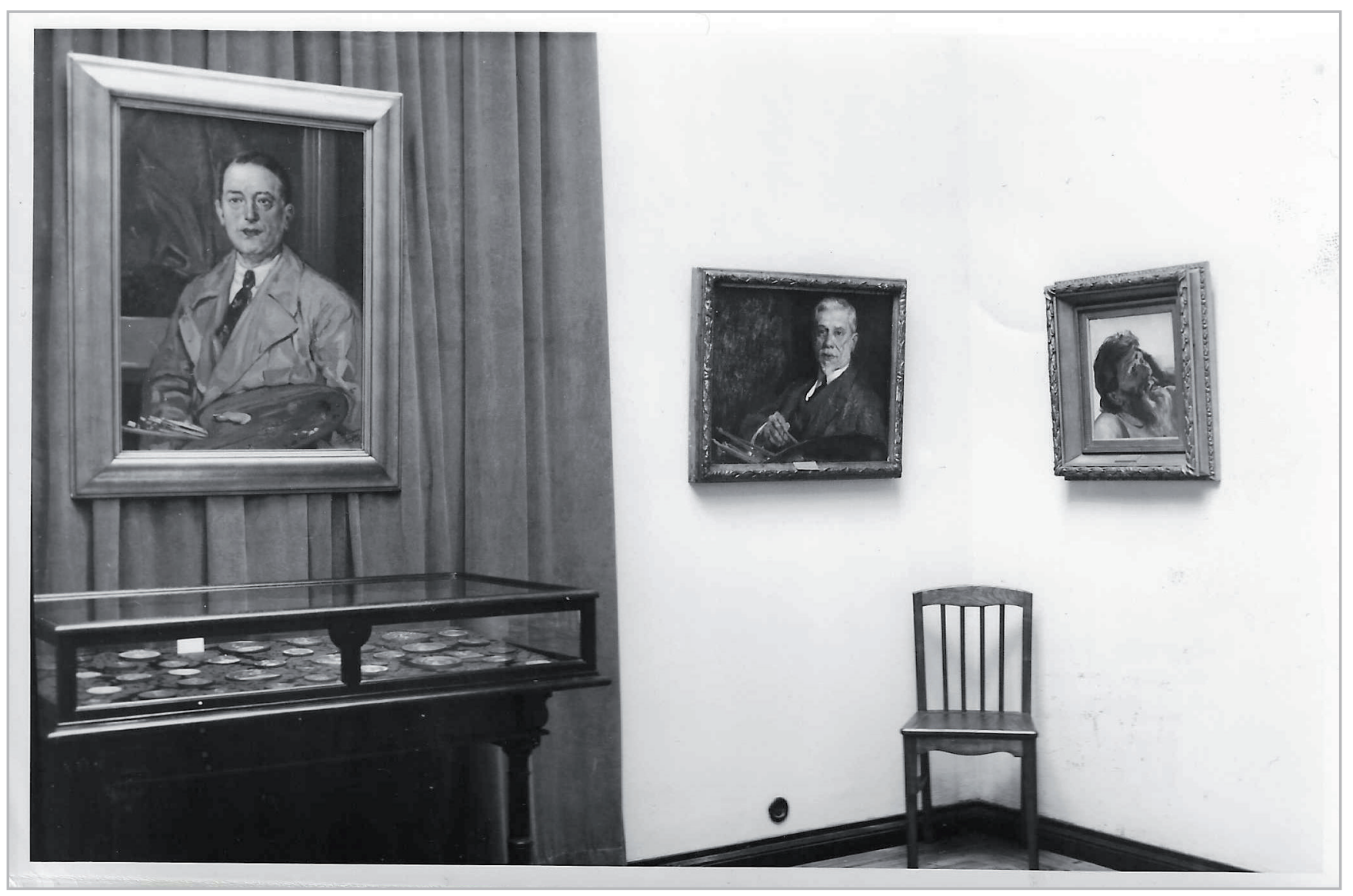

Figura 2.- Fotografia do Retrato de Fernando Mardel (Albino Cunha, 1935) em exposição no Museu de José Malhoa. Fotografia Pereira, c. 1961. @Arquivo familiar dos descendentes de Albino Moreira Cunha.

de Inventário e Beneficiação da Pintura Antiga em Portugal (DGPC, Apontamentos para a História da CR em Portugal).

No início do século XX, em Portugal, o restauro de pintura antiga era ainda uma atividade realizada por pintoresrestauradores e a aprendizagem tinha um caráter oficinal, embora, se começasse a afastar das práticas de caráter empírico que caracterizaram as intervenções dos professores da Academia de Belas-Artes de Lisboa no século anterior (Alves 2011). Nesta oficina, na década de 30, já se começavam a definir as primeiras metodologias de trabalho de caráter mais científico, baseadas no respeito pelo objeto artístico e no estudo técnico e material das pinturas, como noticiava o Diário de Lisboa em 1937: «[...] trabalha-se "cientificamente", sobre o "documento". Cada tábua ou tela que entra na oficina, tem um processo, por vezes volumoso, com radiografias, esquemas e um relatório circunstanciado [...]» (Diário de Lisboa 24/4/1937).

É nesse contexto que em 1937 Albino Cunha, «novo de muito talento», terá iniciado a sua formação em restauro de pintura antiga, através do trabalho realizado juntamente com Luís de Ortigão Burnay (Diário de Lisboa 24/4/1937) e dos conhecimentos que adquiriu com Fernando Mardel, seguindo tradição técnica de Luciano Freire (O Século de 26/1/1971). A colaboração com Fernando Mardel prolongou-se pelo menos até 1939 quando, juntamente com Luís de Ortigão Burnay e João Alves de Sá, foi convidado para colaborar no restauro das pinturas do século XV e XVI que integraram a Exposição dos Primitivos que inaugurou no ano seguinte (Boletim do MNAA 1940).

Nos primeiros anos da década de 1940 participa no restauro das «viaturas» do Museu Nacional dos Coches, juntamente com os pintores Alfredo Cândido e Joaquim Fernandes e com os douradores José Rodrigues Tavares, Manuel António Rodrigues e Pedro de Lemos Correia (Keil 1943; Keil 1944), tendo anteriormente estabelecido parceria com o último durante as obras de restauro do Palácio Nacional de Queluz (SIPA TXT.01751747, SIPA TXT.01751748).

É possível que a partir da década de 1940, Albino Cunha já se estivesse estabelecido como pintor-restaurador com atelier próprio, primeiro na Rua Garrett e depois na Rua Luz Soriano, restaurando obras provenientes de museus, de palácios, de igrejas e de coleções particulares (O Século de 26/1/1971).

Para além deste trabalho em atelier, realizou intervenções in situ em vários palácios lisboetas. Em 1947 restaurou os tetos dos Paços do Concelho, provavelmente as pinturas ornamentais da cúpula, tímpanos e paredes da galeria (CML 1948) e a Sala das Dinastias (SIPA IPA.00020701). No ano seguinte, os tetos do Salão Nobre e da Sala da Música 
do Palácio do Loreto no Chiado (Costa 1957; AA. VV. 1963; Araújo 1952), incluindo as pinturas a óleo sobre tela colocadas sobre madeira Juno Pedindo a Éolo para Libertar os Ventos contra Eneias e Astronomia, Poesia, Música e Pintura (Guerra dos Reis 2006), e os tetos das salas da Ceia, do Trono e D. João IV no Palácio Nacional da Ajuda em 1950 (SIPA IPA.00004722).

Embora os registos consultados apenas documentem a sua colaboração com Fernando Mardel entre 1937 e 1939, atendendo à forte relação de amizade que se estabeleceu entre ambos e que acabaria por se estender às respetivas famílias, é possível que nas décadas de 1940 e de 1950 Albino Cunha tenha angariado vários trabalhos de restauro por intermédio de Fernando Mardel. Provavelmente, realizados fora do contexto institucional, isto é, no seu atelier privado, razão pela qual a sua atividade não é mencionada na documentação do Laboratório de Restauro das Janelas Verdes, numa época em que a secção de pintura continuava a cargo de Fernando Mardel.

Exemplo disto é o processo de adjudicação do restauro da pintura Vitória da Batalha do Salado, da Igreja de São Vicente, em Évora, que primeiramente foi entregue ao «insigne pintor Fernando Mardel» (A Defesa 7/2/1948), que na época era também o responsável pelo restauro das pinturas do século XVI do Museu de Évora (A Defesa 24/1/1948), mas que, segundo a documentação da Câmara Municipal de Évora, acabaria por ser realizado por Albino Cunha, «técnico da especialidade comprovadamente idóneo»(A Defesa, 24/1/1948).

Segundo a documentação existente no arquivo municipal, após este primeiro restauro que foi encomendado por Henrique da Fonseca Chaves, presidente da Câmara Municipal de Évora entre 1946 e 1952 (CME - Galeria dos Presidentes), a Albino Cunha encarregou-se do restauro do pano de boca do Teatro Garcia de Resende em 1953 (Documentos de despesas do ano 1953: Autorização de pagamento n. ${ }^{\circ} 1552$, Autorização de pagamento n. ${ }^{\circ}$ 2894) e dos painéis do retábulo-mor da Ermida de São Sebastião (Livro das Atas das Reuniões, n. 2: fol. 87; Correspondência Expedida de 5/3/952 a 27/8/953: 139; Correspondência Expedida de 5/3/952 a 27/8/953: 13v).

Estes são os últimos registos do seu trabalho como restaurador de que temos conhecimento. Nesta data Albino Cunha tinha 56 anos de idade e é possível que nas décadas seguintes se tenha dedicado à pintura artística e que, por essa razão, a sua atividade como restaurador tenha diminuído.

\section{A prática do restauro}

Ao longo da sua vida, Albino Cunha sempre se assumiu como «pintor d'arte», o que revela a importância que dava à prática artística, a qual certamente influenciou a sua técnica de reintegração cromática, procurando mimetizar a técnica do artista, habilidade pela qual se tornou conhecido.

Na primeira metade do século XX, os critérios de intervenção e os objetivos da reintegração cromática começavam a ser definidos em normativas e diretrizes internacionais. No entanto, existia ainda uma tendência em integrar as partes novas «em conformidade com os restantes antigos ainda existente», como se pode ler na proposta que Albino Cunha apresentou para a intervenção no Quarto de Toillette de D. Carlota Joaquina, no Palácio Nacional de Queluz em 1934 (SIPA TXT.01751720).

A sua passagem pela Oficina de Restauro de Fernando Mardel, onde «não se pinta, não se repinta» (Diário de Lisboa 24/4/1937), alterou certamente a sua abordagem, acrescentando uma vertente mais científica à sua forma de intervir na pintura antiga.

Numa época em que os restauradores eram pintores e os pintores também se dedicavam ao restauro de obras de arte, eram debatidas várias questões técnicas e definidos critérios de intervenção em encontros internacionais (Burnay 1935), o que em muito contribuiu para o reconhecimento da «[...] necessidade de utilizar processos científicos [...]» (Couto 1948). Apesar desses progressos, em muitas intervenções de restauro, como a levada a cabo no Museu dos Coches, procurava-se «restituir o que faltava sem alterar o que ainda existia» e "restaurar com critério o que estava quase sem tocar na execução coeva, reintegrando os carros no seu aspeto primitivo» (Keil 1944).

Para além dos trabalhos levados a cabo em contexto museológico ou na oficina de restauro do Estado, a informação que dispomos sobre a metodologia e os critérios de intervenção aplicados no restauro de pintura de cavalete por Albino Moreira da Cunha no seu atelier privado é parca e dispersa. Uma exceção a isso encontra-se na documentação existente sobre o restauro das pinturas retabulares das ermidas de São Sebastião e de São Vicente, em Évora, anteriormente referidas, que revelam que no seu atelier particular a reintegração cromática era influenciada pela sua prática como pintor, apesar do carácter mais científico dado ao estudo e à documentação das obras.

No restauro das pinturas do retábulo-mor da Ermida de São Sebastião [Figura 3], o pintor-restaurador considerou que perante «[...] a impraticabilidade de uma restituição absoluta das formas primitivas da pintura a reconstituição era fatal e justa dentro dos moldes ambientes, críticos e modernos. [...] e sempre observando o caráter primitivo da composição [...] as tintas [foram] fixadas e reintegradas na composição e cor originais [...]» (Espanca 1954).

Se por um lado a metodologia utilizada beneficiou da sua formação artística e da experiência como pintor-decorador, notória nos trabalhos de restauro dos tetos dos palácios lisboetas, será necessário um estudo mais aprofundado sobre as técnicas e os materiais utilizados no restauro das pinturas retabulares eborenses para percebermos o impacto 


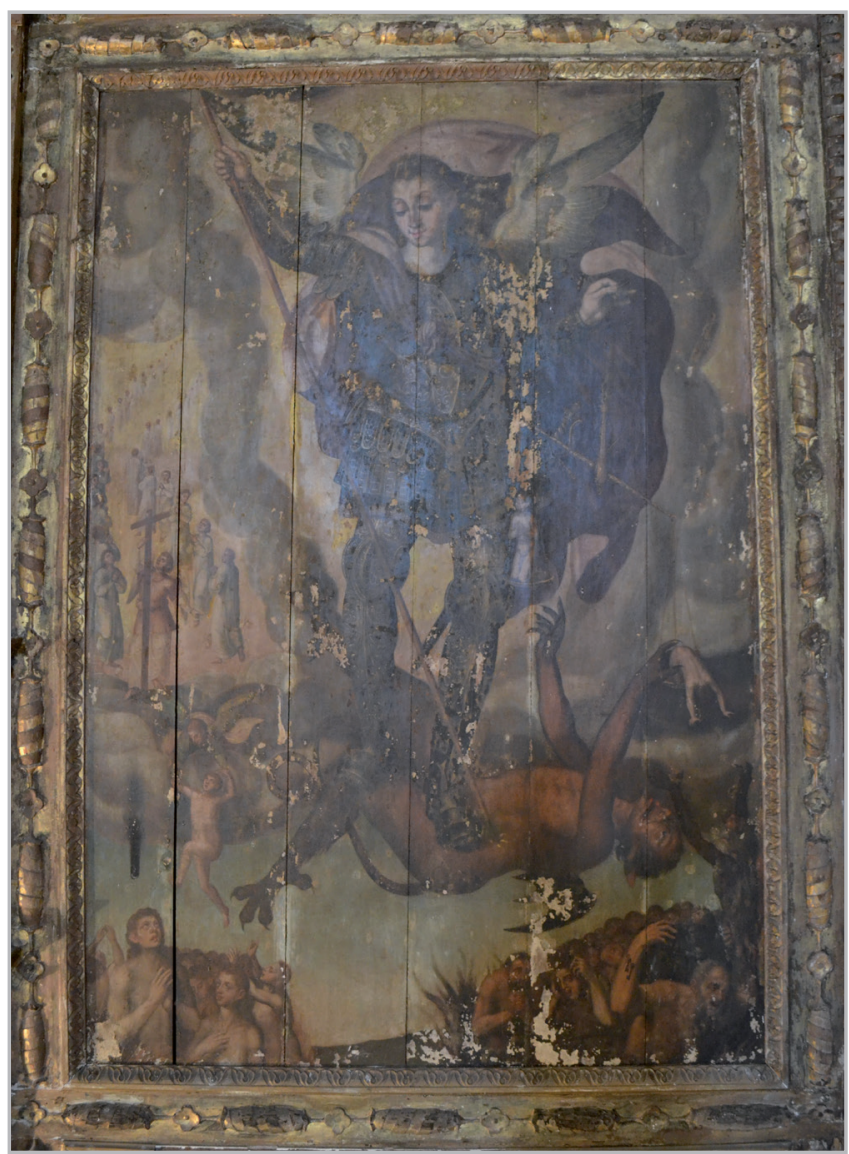

Figura 3.- Pintura São Miguel Arcanjo pesando as Almas. Retábulomor da Ermida de São Sebastião, Évora. @V. G. Nascimento 2018.

da sua formação na oficina de Fernando Mardel na escolha dos materiais e da metodologia de intervenção a seguir.

Como estas obras constituem o derradeiro registo do seu trabalho, só poderemos esclarecer estas questões com um estudo comparativo da sua obra pictórica e das pinturas que restaurou, para que, através do estudo técnico e material, possamos caracterizar a sua abordagem em cada uma das práticas.

\section{Conclusão}

Ao longo da sua vida Albino Moreira da Cunha assumiu-se como "pintor d'arte" e não como pintor-restaurador, muito embora tenha levado a cabo vários trabalhos de restauro a partir da década de 1930, depois da sua chegada a Lisboa.

Após a sua morte em 1970, este pintor naturalista, decorador e restaurador, acaba por cair no esquecimento, 0 que não deixa de ser surpreendente se tivermos em conta a sua vasta produção pictórica e a sua participação em várias exposições em Portugal e no estrangeiro. A popularidade que alcançou como artista e a sua notoriedade como restaurador valeram-lhe uma entrada na Enciclopédia Luso-Brasileira de 1963, o que é bem demonstrativo da sua importância no contexto artístico e cultural da época.
No entanto, a sua atividade como restaurador de pintura antiga passou completamente despercebida, facto que poderá estar relacionado com o seu trabalho ter sido realizado de forma autónoma, em atelier privado, mas que não explica a falta de referências à sua prestação na Oficina de Restauro do Estado entre 1937 e 1940, ou no Museu dos Coches nos anos seguintes. É possível que a ligação que estabeleceu com Fernando Mardel o tenha remetido para segundo plano na história do restauro, face à importância que o seu mestre e amigo alcançou nessa época, e que continua a ter atualmente. Não podemos ignorar que a partir da década de 1960, isto é, após a morte de Mardel, e até à data da sua morte em 1970 (Diário de Lisboa 12/4/1970) as referências a Albino Cunha nas fontes documentais são quase inexistentes.

A pouca informação disponível sobre a sua vida e obra deixam por esclarecer a influência da prática pictórica na sua atividade como restaurador, ficando o nosso contributo limitado à interpretação e análise da documentação conhecida e disponível para consulta.

A história do restauro em Portugal beneficiaria de uma investigação aprofundada sobre a sua atividade na oficina de Fernando Mardel, nos restauros in situ dos tetos dos palácios lisboetas e no seu atelier privado, a partir da qual poderia ser estabelecido um paralelo entre as metodologias e as técnicas aplicadas na Oficina de Restauro do Estado e nos ateliers privados dos pintores-restauradores portugueses em meados do século XX.

\section{Agradecimentos}

Os autores agradecem a colaboração da família de Albino Moreira da Cunha, dos conservadores-restauradores Francisca Figueira e Raul Leite (Laboratório José de Figueiredo), do Dr. Luís Montalvão (Biblioteca do Museu Nacional de Arte Antiga), da Dra. Rosário Martins (Arquivo da Câmara Municipal de Évora) e da equipa do Jornal $A$ Defesa.

Este artigo é o resultado do trabalho desenvolvido com o apoio técnico do Laboratório HERCULES da Universidade de Évora e do CIEBA da Faculdade de Belas-Artes da Universidade de Lisboa, como parte do projeto de investigação integrado no Programa Doutoral HERITAS - Estudos de Património (PD/00297/2013) e financiado pela FCT - Fundação para a Ciência e Tecnologia (PD/ BI/114472/2016; PD/BD/135144/2017).

\section{Notas}

[1] Leal da Câmara (1876-1948) foi um pintor português que ocupou um lugar de destaque no panorama português da primeira metade do século XX. Terá sido durante o período em que viveu no Porto, e onde deu aulas nas Escolas Infante D. Henrique e Faria de Guimarães (CMS; CMS-museuvirtual), que terá conhecido Albino 
Moreira da Cunha com que colaborou na Exposição do Rio de Janeiro em 1922. Nessa exposição internacional foi responsável pela pintura das barras decorativas dos torreões e das galerias de artes aplicadas do Pavilhão das Grandes Indústrias Portuguesas (Rodrigues 2013).

[2] O Salão Bobone localizava-se em Lisboa, na Rua Serpa Pinto, e pertencia ao fotografo Augusto Bobone (1825-1910). Nas primeiras décadas do século $X X$, acolheu várias exposições de artistas, como a de Diogo de Macedo em 1928.

[3] Segundo Paula Mesquita Leite Santos, no seu artigo sobre Jean Pillement e os colecionadores do Porto, entre 1927 e 1963, Albino Moreira da Cunha participou em várias exposições individuais (1935 e 1946) e coletivas (1927 e 1959) organizadas pela SNBA e em 1937 a sua obra integra a "I Retrospetiva da Arte Portuguesa" organizada pela SNBA. Ao longo dos anos expões também em Lisboa (1952 e 1953), no Casino Estoril (1932, 1936, 1938, 1940, 1947, 1948 e 1951) e em Vila Franca de Xira (1954) (Santos 2020).

[4] João Marques de Oliveira (1853-1927) estudou na Academia Portuense de Belas-Artes, onde frequentou o curso de Pintura de História, e na École des Beaus-Arts em Paris, como bolseiro do Estado Português. Lecionou as cadeiras de Pintura Histórica e de Desenho Histórico, ocupando também o cargo de Diretor da Academia Portuense. Dedicou-se ao retrato e à pintura de paisagem, e a sua participação ativa no meio artístico e cultura contribuiu para a divulgação de uma estética naturalista (MNAC - Silveira, Oliveira).

[5] Joaquim Lopes (1886-1956) foi aluno de Marques de Oliveira no curso de pintura da Academia Portuense de Belas-Artes, que termina em 1915. Em 1919 vai para Paris para estudar pintura na Academia Grand Chaumière e após regressar a Portugal dedica-se ao ensino de pintura na Escola de Belas-Artes do Porto. Em 192223 representou Portugal na Exposição Internacional do Rio de Janeiro. (UP - Universidade Digital / Gestão de Informação 2008).

\section{Referências}

ACCIAOUOLI, M. M. (1991). "Os anos 40 em Portugal, O país, o regime e as artes: «restauração» e "celebração»", Volume II documentos, Dissertação de Doutoramento em História da Arte contemporânea, Faculdade de Ciências Sociais e Humanas, Universidade Nova de Lisboa. http://hdl.handle.net/10362/14822, [consulta: 30/5/2021].

$A B C$ (1947).“"Revista de pintores" $A B C$ Madrid, 8/7/1947, 11. https:// www.abc.es/archivo/periodicos/abc-madrid-19470708-11.html, [consulta: 1/2/2020].

ALVES, A. N. (2011). "As práticas do restauro em Belas-Artes". Em O Restauro regressa às Belas-Artes. Lisboa: Faculdade de Belas-Artes da Universidade de Lisboa, CIEBA. p.36-42- http://hdl.handle. net/10451/6709 [consulta: 30/5/2021].

ARAÚJO, N. (1952). Inventário de Lisboa, fascículo 9, Câmara Municipal de Lisboa". http://hemerotecadigital.cm-lisboa.
pt/Periodicos/InventariodeLisboa/Fasc09/Fasc09 master/ InventariodeLisboa Fasc09.pdf, [consulta: 6/5/2020].

AA.VV. (1963). Enciclopédia Luso Brasileira, Verbo.

BENEZIT, E. (1976). "Dictionnaire des peintures, sculpteurs, dessinateurs et graveurs", 3, CHILL-DUG, Librairie Grund.

Boletim dos Museus Nacionais de Arte Antiga (1940) n. ${ }^{\circ}$ 3. Vol. I, Lisboa, http://hemerotecadigital.cm-lisboa.pt/, [consulta: $5 / 5 / 2020]$.

BRITO, M. M. A. (1991). "Os anos 40 em Portugal, o país, o regime e as artes: «restauração» e "celebração»". Volume II - documentos. Dissertação de Doutoramento em História da Arte Contemporânea, Faculdade de Ciências Sociais e Humanas, Universidade Nova de Lisboa, http://hdl.handle. net/10362/14822, [consulta: 5/5/2020].

CME - Câmara Municipal de Évora (2015). Galeria dos Presidentes. https://www.cm-evora.pt/wp-content/uploads/2020/07/ galeriapresidentesCME2015.pdf, [consulta: 30/5/2021].

CML - Câmara Municipal de Lisboa (1954). Anais do Município de Lisboa 1953. http://hemerotecadigital.cmlisboa.pt/OBRAS/AnaisMunicipio/1953/1953 master/ AnaisdoMunicipiodeLisboa1953.pdf, [consulta: 5/5/2020].

CMS - Câmara Municipal de Sintra. Casa-Museu Leal da Câmara. https://cm-sintra.pt/atualidade/cultura/museus-municipais-desintra/casa-museu-de-leal-da-camara. [consulta: 25/5/2021].

CMS - Câmara Municipal de Sintra. Museu Virtual Casa-Museu Leal da Câmara. http://museuvirtual.cm-sintra.pt/cmlc/. [consulta: 25/5/2021].

Cinéfilo (1929). Vol. 2, Edições 20-45, Sociedade Nacional de Tipografia.

Comissão Nacional dos Centenário (1940). Casa de Santo António, http://tribop.pt/MB/murais/m01/Expo1940-Comiss\%C3\%B5es-. pdf, [consulta:5/5/2020].

COSTA, M. (1957). “O Palácio do Loreto". Olisipo, Boletim Trimestral do Grupo de Amigos de Lisboa. Ano XX, n. ${ }^{\circ}$ 79, Julho de 1957, 113-130. http://hemerotecadigital.cm-lisboa.pt/Periodicos/ Olisipo/1957/N79/N79 master/Olisipo N79 Jul1957.PDF, [consulta: 5/5/2020].

COUTO, J. (1948). "A ação dos físicos e dos químicos nos laboratórios dos museus de arte", Gazeta da Física, Vol. I, Fasc. 6 de Janeiro de 1948, 161-167.

DGPC - Direção-Geral do Património Cultural. Conservação e Restauro / Laboratório José de Figueiredo: Apontamentos para a História da CR em Portugal. http://patrimoniocultural.gov. pt/pt/patrimonio/conservacao-e-restauro-laboratorio-josede-figueiredo/apontamentos-para-historia-da-conservacao-erestauro-em-portugal/, [consulta: 25/5/2021]. 
DGPC - Direção-Geral do Património Cultural. MatrizNet, Museu do Chiado - Museu Nacional de Arte Contemporânea. http:// matriznet.dgpc.pt/, [consulta: 25/5/2021].

DGPC - Direção-Geral do Património Cultural. MatrizNet, Museu José Malhoa. http://matriznet.dgpc.pt/, [consulta: 25/5/2021].

DGPC - Direção-Geral do Património Cultural. MatrizNet, Palácio Nacional de Arte Antiga. http://matriznet.dgpc.pt/, [consulta: 25/5/2021].

ESPANCA, T. (1954). "A ermida de São Sebastião: Sua evolução histórica". A Defesa, n. ${ }^{\circ}$ 938, Ano XXVI, 19 de Janeiro de 1954. Évora, Arquivo do Jornal a Defesa.

Europeana. Albino Cunha. https://www.europeana.eu/pt/sea rch?page $=1 \&$ view=grid\&query=Albino $\% 20$ Cunha, $\quad$ [consulta: 5/5/2020].

Évora, Arquivo da Câmara Municipal de Évora. "Correspondência Expedida de 5/3/952 a 27/8/953".

Évora, Arquivo da Câmara Municipal de Évora. "Livro das Atas das Reuniões, n. 2 - Comissão Municipal de Turismo (24/4/943 a 13/5/960)".

Évora, Arquivo da Câmara Municipal de Évora. “Documentos de despesas do ano 1953, Capítulo 80 - Gerência de 1/1/1953 a 31/12/1953".

Évora, Arquivo da Câmara Municipal de Évora. "Expediente Cx. 9, Diversos de 1952-1953".

Évora, Arquivo do Jornal a Defesa. , A Defesa, 24/1/1948, n. 1298 , Ano XXIV.

Évora, Arquivo do Jornal a Defesa. A Defesa 17/2/1948, n. 1300, Ano XXV.

Faculdade de Belas-Artes do Porto (FBAP). Inventário Alumni (1836-1957). http://arquivo.fba.up.pt/docs/Alumni_1836 1957. pdf, [consulta: 4/5/2020].

GUERRA DOS REIS, V. M. (2006). O rapto do observador: invenção, representação e percepção do espaço celestial na pintura de tectos em Portugal no século XVIII. Tese de Doutoramento em BelasArtes, Vol.2, Universidade de Lisboa, Faculdade de Belas-Artes, http://hdl.handle.net/10451/2051, [consulta: 5/5/2020].

llustração n. 97, 1/1/1930, 5. ano, Lisboa. http:// hemerotecadigital.cm-lisboa.pt/OBRAS/llustracao/1930/N97/ N97 item1/P23.html, [consulta: 4/5/2020].

Ilustração n. 200, 16/4/1934, Lisboa. http://hemerotecadigital. cm-lisboa.pt/OBRAS/llustracao/1934/N200/N200 master/N200. pdf, [consulta: $26 / 5 / 2021]$.

Ilustração n. ${ }^{\circ}$ 249, 5/1936, 11. ${ }^{\circ}$ ano, Lisboa. http:// hemerotecadigital.cm-lisboa.pt/OBRAS/Ilustracao/1936/N249/
N249 master/N249.pdf, [consulta: 26/5/2021].

Lisboa, Arquivo do Ginásio Clube Português. Fundo de Ficha de Identificação do Ginásio Clube Português, PT-GCP/FIS/5095.

Lisboa, Arquivo Nacional Torre do Tombo - DigitArq. Arquivo José de Figueiredo. BURNAY, L. O. (1935). "Relatório geral sobre as observações colhidas no que respeita a conservação e restauro das pinturas e obtidas por ocasião do congresso internacional de museologia realizado em outubro de 1934 em Madrid". 20 de dezembro de 1935, p.2-10, PT/MNAA/AJF/ APF-MNAA-R/001/00001/000002. http://digitarq.arquivos.pt/ details?id=4739500, [consulta: $14 / 2 / 2018$ ].

Lisboa, Biblioteca da Arte - Fundação Calouste Gulbenkian. Coleção Diogo e Eva de Macedo. "Catálogo da Exposição de Pintura de Albino Cunha no Salão "Silva Porto»". Porto, Março de 1949. Oficinas Gráficas da Rádio Renascença, Lisboa, 1949 (exemplar policopiado).

Lisboa, Biblioteca da Arte - Fundação Calouste Gulbenkian, Coleção Diogo e Eva de Macedo. Diário de Lisboa 12/4/1970, Necrologia - Albino Moreira da Cunha (recorte).

Lisboa, Biblioteca da Arte - Fundação Calouste Gulbenkian, Coleção Diogo e Eva de Macedo. Quadros, móveis e faianças do espólio do pintor e restaurador mestre Albino Cunha vão ser leiloados, O Século, 26 de Janeiro de 1971 (recorte).

Lisboa, Fundação Mário Soares - Documentos Ruella Ramos. "A pintura revelada pela ciência: Há em Lisboa um "hospital" de quadros". Diário de Lisboa, n. ${ }^{\circ}$ 5182. Ano 17, 24 de Abril de 1937. http://hdl.handle.net/11002/fms dc 27238, [consulta: 9/5/2020].

KEIL, L. (1943). "Algumas considerações históricas e artísticas acerca dos coches e do seu museu - origens, ampliações e restauros". Separata do Boletim N.o 12 da Academia Nacional de Belas-Artes), Bertrand, Lisboa.

KEIL, L. (1944). "Palavras preferidas na inauguração das novas instalações do Museu Nacional dos Coches, 29 de Abril de 1944". Bertrand, Lisboa.

MNAC - Museu Nacional de Arte Contemporânea, SILVEIRA, M. A., OLIVEIRA, J. M..Voltar à Coleção - João Marques de Oliveira. http://www.museuartecontemporanea.gov.pt/pt/artistas/ ver/22/artists, [consulta: 30/5/2021].

MOREIRA LOBO, M. A. M. (1998). "O ensino das artes aplicadas (ourivesaria e talha) na escola Faria Guimarães de 1884 a 1948: Reflexo no desenvolvimento artístico da cidade do Porto". Dissertação de Mestrado em História da Arte, Faculdade de Letras da Universidade do Porto. http://hdl.handle.net/10216/19457, [consulta: 4/5/2020].

MORAZA, J.L. (2010). El retorno de lo imaginario - Realismos entre XIX y XX (Tributo a Juan Antonio Ramírez). Comissário Juan Luis Moraza, Museo Nacional Centro de Arte Reina Sofía (MNCARS) 19 
de maio - 30 de agosto de 2010. https://www.museoreinasofia. es/sites/default/files/exposiciones/folletos/el retorno de lo imaginario.pdf, [consulta: 26/5/2021].

Museu de Lisboa - Coleção online. Retrato de Gustavo de Matos Sequeira. http://acervo.museudelisboa.pt/ficha.aspx?sugestao= 1 \&ns $=216000 \& i d=64351 \&$ museu $=2$, [consulta: $24 / 5 / 2021$ ].

Olisipo n. 3, 8/1938, ano I. Grupo «Amigos de Lisboa», Lisboa. $\quad$ http://hemerotecadigital.cm-lisboa.pt/Periodicos/Olisipo/1938/N03/N03 master/Olisipo N03 Ago1938.pdf, [consulta: 24/5/2021].

Panorama - Revista Portuguesa de Arte e Turismo n. ${ }^{\circ 17}$, 1960, III série. Secretariado da Propaganda Nacional. [consulta: 5/5/2020].

PEREZ, M. F. H. P. (2012). Adriano de Sousa Lopes, director do Museu Nacional de Arte Contemporânea: entre a comunidade e a mudança. Tese de Mestrado em Museologia na Faculdade de Ciências Sociais e Humanas da Universidade Nova de Lisboa. http://hdl.handle.net/10362/7982, [consulta: 6/5/2020].

Revista dos centenários, n. 19 31/7/1940 e n.` 20 31/8/1940, ano II. Comissão Executiva dos Centenários, Secção de Propaganda e Recepção - Redacção, Secretariado da propaganda Nacional, Lisboa. http://hemerotecadigital.cm-lisboa.pt/Periodicos/ RevistadosCentenarios/N19 20/N19 20 item1/P1.html, [consulta: 5/5/2020].

RODRIGUES, M. G. (2013). A participação portuguesa nas exposições universais na perspectiva do design de equipamento. Tese do Mestrado em Design de Equipamentos da Faculdade de Belas-Artes da Universidade de Lisboa. https://repositorio.ul.pt/ bitstream/10451/15343/2/ULFBA TES\%20752.pdf, [consulta: 4/5/2020].

SANTOS, P. M. L. (2020). "Jean Pillement (Lyon, 1728-1808) e os colecionadores do Porto. Pintura nos Museus Nacionais de Soares dos Reis e de Arte Antiga". MIDAS 11 https://doi.org/10.4000/ midas.2171, [consulta: 26/5/2021].

Seara Nova 803-854 1943, Empresa de Publicidade "Seara Nova". https://books.google.pt/books?id=8MM5AQAAIAAJ\&q=\%2 2Albino+Cunha $\% 22 \& d q=\% 22$ Albino + Cunha $\% 22 \&$ hl=pt-PT, [consulta: 26/5/2021].

Seara Nova 908-959 1945, Empresa de Publicidade "Seara Nova". https://books.google.pt/books?hl=pt-PT\&id=HsY5AQAAIAAJ\&d $\mathrm{q}=$ pintura $\% 22 \mathrm{Albino}+$ Cunha\%22\&focus=searchwithinvolume \&q=\%22amesquinhada\%22, [consulta: 26/5/2021].

SIPA - Sistema de Inventário do Património Arquitetónico. IPA.00004722 - Palácio Nacional da Ajuda. www.monumentos. pt, [consulta: 5/5/2020].

SIPA - Sistema de Inventário do Património Arquitetónico. IPA.00006108 - Palácio Nacional de Queluz. www.monumentos. pt, [consulta: 5/5/2020].
TACÃO, S. (2010). "Arte e Medicina - Representação do Corpo Humano na Coleção Ceroplástica do Museu Sá Penella, Hospital dos Capuchos". Seminário Património Hospitalar de Lisboa: Que futuro? 2 e 3 de dezembro de 2010, Lisboa, FA-UTL/CIAU; ICOMOS Portugal, CHLC, http://icomos.fa.utl.pt/documentos/2010/ hospitalar/SandraTacao\%20Arte\%20e\%20Medicina.pdf, [consulta: 19/1/2020].

UP - Universidade do Porto, Universidade Digital / Gestão de Informação (2008). Antigos Alunos Ilustres da Universidade do Porto, Joaquim Lopes. https://sigarra.up.pt/up/pt/web base. gera pagina?p pagina=antigos $\% 20$ estudantes $\% 20$ ilustres $\% 20$ -\%20joaquim\%20lopes, [consulta: 29/5/2021].

\section{Autor/es}

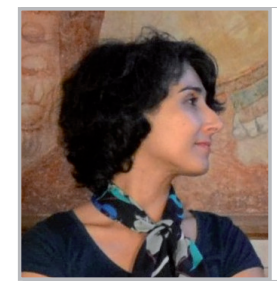

\section{Virgínia Glória Nascimento}

vgloriaanascimento@gmail.com

Universidade de Lisboa, Faculdade de BelasArtes, Centro de Investigação e de Estudos em Belas-Artes (CIEBA)

https://orcid.org/0000-0003-3562-4959

É doutoranda do Programa Doutoral HERITAS - Estudos de Património (PD/BI/114472/2016; PD/BD/135144/2017), dedicando-se desde 2015 às questões da salvaguarda e do uso do património integrado em edifícios religiosos. No âmbito profissional integrou equipas multidisciplinares em intervenções de conservação e restauro de pintura de cavalete, realizadas in situ e em ambiente museológico, no seguimento da formação em conservação e restauro e em museologia e museografia.

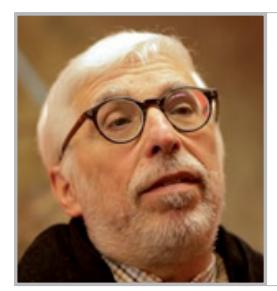

Fernando António Baptista Pereira

fernandoabpereira@gmail.com Universidade de Lisboa, Faculdade de Belas-Artes, Centro de Investigação e de Estudos em Belas-Artes (CIEBA) https://orcid.org/0000-0001-9308-7915

É licenciado em História pela Faculdade de Letras da Universidade de Lisboa, pós-graduado em Museologia pelo antigo Instituto Português do Património Cultural e doutorado em Ciências da Arte (História da Arte) pela Faculdade de BelasArtes da Universidade de Lisboa. Ensina na Universidade de Lisboa (na Faculdade de Letras e na Faculdade de Belas-Artes) desde 1979, sendo atualmente Professor Associado na de Belas-Artes, onde desempenhou as funções de Presidente do Conselho Científico, de Diretor do Centro de Investigação e Estudos em Belas-Artes (CIEBA), sendo também o autor do Plano de Estudos da Licenciatura em Ciências da Arte e do Património dessa faculdade. Tem vasta e diversificada obra publicada nos domínios da História da Arte e da Cultura Portuguesas, da Crítica de Arte e da Museologia. Foi Assessor do Ministro da Cultura para o Património e Museus e é atualmente presidente da Faculdade de Belas-Artes da Universidade de Lisboa. 


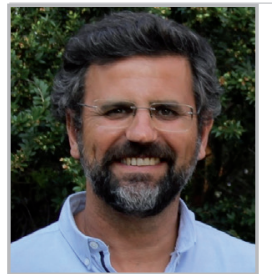

\section{António Candeias}

candeias@uevora.pt

Laboratório HERCULES, City University

of Macau chair in Sustainable Heritage,

Universidade de Évora

https://orcid.org/0000-0002-4912-5061

É químico especializado em química de superfícies e ciências do património. Professor da Universidade de Évora desde 1992, foi diretor do Laboratório HERCULES desde a sua criação em janeiro de 2009 até fevereiro de 2019. Atualmente é Vice-Reitor para a Investigação e Desenvolvimento e Diretor do Instituto de Investigação e Formação Avançada da Universidade de Évora, Director da infraestrutura nacional ERIHS.pt (plataforma portuguesa da European Infrastructure in Heritage Sciences) e Coordenador da Cátedra CityUMacau em "Sustainable Heritage".

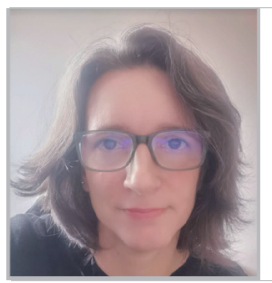

\section{Alice Nogueira Alves}

a.alves@belasartes.ulisboa.pt

Universidade de Lisboa, Faculdade de Belas-Artes, Centro de Investigação e de Estudos em Belas-Artes (CIEBA) https://orcid.org/0000-0001-6683-8007

É conservadora restauradora. Desde o início da sua formação, as questões relacionadas com a história e a teoria do restauro e o modo como se encara o objeto artístico assumiram uma importância fundamental nos seus interesses académicos, terminando o seu doutoramento História da Arte, Património e Teoria do Restauro, na Faculdade de Letras da Universidade de Lisboa, em 2009. Atualmente, é Professora Auxiliar Convidada da Faculdade de BelasArtes da Universidade de Lisboa.

Artículo enviado el24/07/2021 Artículo aceptado el 07/10/2021

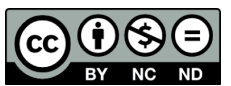

https://doi.org/10.37558/gec.v20i.1025 